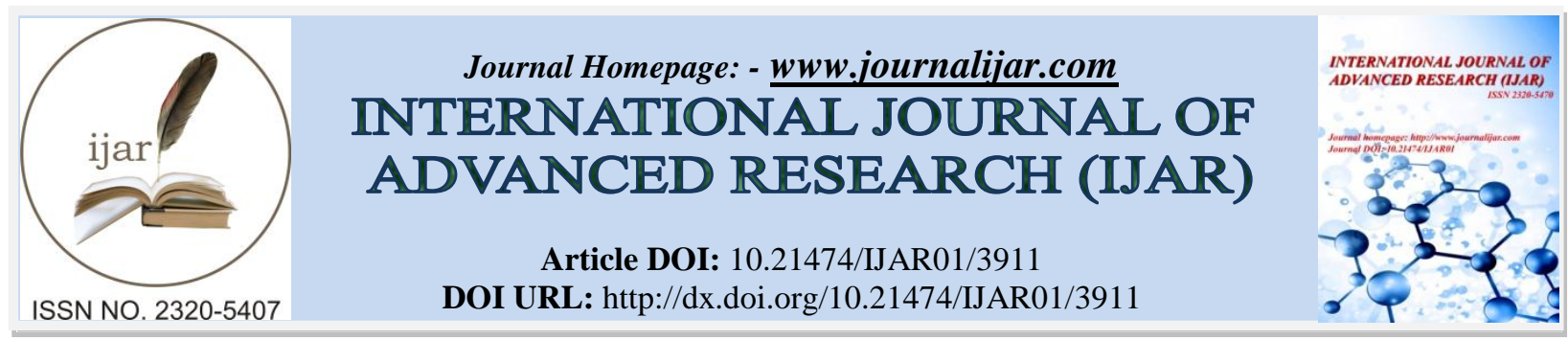

RESEARCH ARTICLE

\title{
CLINICAL EXAMINATION LOST ART IN MEDICINE? : DIAGNOSTIC ROLE OF VENOUS COLLATERALS IN DETERMINING PROXIMAL VENOUS OBSTRUCTION.
}

"Dr. Thulasikumar. G' ${ }^{1}$ Dr. Elancheralathan. $\mathbf{K}^{\mathbf{1}}$, Dr. Deepan kumar. B ${ }^{1}$, Dr. Ashok kumar. ${ }^{2}$, Dr. Shanmughavelayutham. $C^{\mathbf{1}}$ and Dr. Lakshmi dharan. $\mathbf{M}^{\mathbf{1}}$.

1. Department of Vascular Surgery, Stanley Medical College, Chennai.

2. Department of Vascular Surgery, Thanjavur Medical College, Thanjavur.

\section{Manuscript Info}

Manuscript History

Received: 15 February 2017

Final Accepted: 18 March 2017

Published: April 2017

Key words:-

Clinical Examination, Venous

Collaterals, Venous Obstruction

\section{Abstract}

Introduction: In this era of advanced medicine, the role of basic clinical examination is a forgotten art. Aim of the study is to determine the diagnostic role of visible venous collaterals determined by clinical examination in diagnosis of proximal venous obstruction.

Material and Methods: This is an observational study done in 30 patients with venous leg ulcers in the past two years (2015-16). These patients were thoroughly examined clinically for visible venous collaterals. Confirmation of proximal venous obstruction is by means of CT or Conventional Venogram.

Results: Out of 30 patients, 9 were found to have visible venous collaterals on clinical examination. 17 patients were confirmed to have proximal venous obstruction. All of these nine patients with venous collaterals found to have proximal venous obstruction. In our study, specificity and positive predictive value of the clinically visible venous collateral vein were found to be $100 \%$ each.With sensitivity and negative predictive values $52.94 \%$ and $61.9 \%$ respectively.

Conclusion: Thus clinically visible venous collaterals in patients with venous leg ulcers are highly specific in diagnosing proximal venous obstruction. Emphasizing the fact that even in this era of advanced diagnostic modalities, basic clinical examination skills still holds good.

Copy Right, IJAR, 2017,. All rights reserved.

\section{Introduction:-}

In this era of advanced medicine with highly sophisticated diagnostic modalities with increased cost and complexity, simple basic clinical examination is a lost art. This study is about the diagnostic role of clinically visible venous collaterals in diagnosis of proximal venous obstruction.

Chronic venous disease including varicose veins is an extremely common medical condition that has a significant impact on an individual's health and the health care system. Deep venous obstructive disease in combination with venous insufficiency has been noted in up to $55 \%$ of patients with CVI, especially in those with the most severe symptoms. ${ }^{8}$

Venous ulcers are the most common form of leg ulcers. ${ }^{2}$ Prompt diagnosis of proximal venous obstruction in patients with venous leg ulcers, helps to correct the disease and prevent devastating effects of mere superficial 
varicose surgery without correcting proximal venous obstruction. With effective treatment options available to treat proximal venous obstruction, especially less morbid minimally invasive Percutaneous endovenous stenting which has emerged as a powerful technique to treat chronic venous obstructions, ${ }^{9}$ it should be detected promptly and treated.

\section{Materials and methods:-}

It is a prospective observational study conducted in those patients with venous leg ulcers who were reported to vascular surgery outpatient department during the past two years (2015-16). These patients were thoroughly examined for visible venous collaterals. Sites for Visible venous collaterals were groin, pubic region, scrotal skin and abdominal wall (anterior and lateral). Confirmation of proximal venous obstruction is by means of CT/MR Venogram or Conventional venogram. As venographic characteristics of these venous collaterals has been well described. 6,10

\section{Results and discussion:-}

In the last decade, the importance of venous obstruction and particularly that of iliac vein obstruction in the genesis of chronic venous disease symptoms has become recognized. ${ }^{1}$ Although various diagnostic modalities are available in detecting proximal venous obstruction, those with higher accuracy in detecting including CT/MR venography, Conventional Venography and Intra vascular ultrasound have issues in form of cost effectiveness, radiation exposure and availability. Hence these tests cannot be applied to all patients with venous disease due to above issues. These tests can be effectively utilized when other simpler tests are used to isolate patients to very high probability for proximal venous obstruction, such that above tests can be selectively employed to have best possible outcome.

Presence of collaterals has been suggested to be of hemodynamic importance. ${ }^{4} 7$ In these respect, physical examination for visible venous collaterals can be done simply in all patients with venous disease without any cost concern or radiation exposure to aid in diagnosing/ categorizing as higher probability for proximal venous obstruction. Characteristic findings are shown in tables 1 and 2.

Table 1:- Characteristics Of Patients With Venous Collaterals.

\begin{tabular}{|l|l|l|l|}
\hline S.NO. & FEATURES & NUMBER & PERCENTAGE \\
\hline 1. & MEAN AGE ( 25 - 49 YEARS) & 38.5 YEARS & - \\
\hline 2. & GENDER: A) MALE & $7 / 9$ & $77.78 \%$ \\
& \multicolumn{1}{|c|}{ B) FEMALE } & $2 / 9$ & $22.22 \%$ \\
\hline 3. & INCIDENCE OF COLLATERALS: & & $52.94 \%$ \\
& A) IN VENOUS OBSTRUCTION GROUP & $9 / 17$ & $30 \%$ \\
& B) IN VENOUS LEG ULCER GROUP & $9 / 30$ & $53.33 \%$ \\
\hline 4. & C) IN DEEP VENOUS THROMBOSIS GROUP & $9 / 15$ & $88.89 \%$ \\
\hline 5. & PREVIOUS HISTORY OF DVT & $8 / 9$ & $11.11 \%$ \\
& SIDE OF LIMB EFFECTED: & $1 / 9$ & $77.78 \%$ \\
& A) RIGHT SIDE & $7 / 9$ & $11.11 \%$ \\
\hline
\end{tabular}

Out of thirty patients with venous leg ulcers, nine patients were found to have visible venous collaterals with incidence of $30 \% .17$ patients were confirmed to have proximal venous obstruction. All of these nine patients with venous collaterals found to have proximal venous obstruction with incidence in venous obstruction group for collaterals were $52.94 \%$.

\section{Sensitivity and specificity of clinical venous collaterals:-}

In our study, Sensitivity and negative predictive value of the venous collateral vein for proximal obstruction was $52.94 \%$ and $61.9 \%$ respectively. But specificity and positive predictive value were $100 \%$ each .

Table 2:- Venous Collaterals In Venous Obstruction Patients

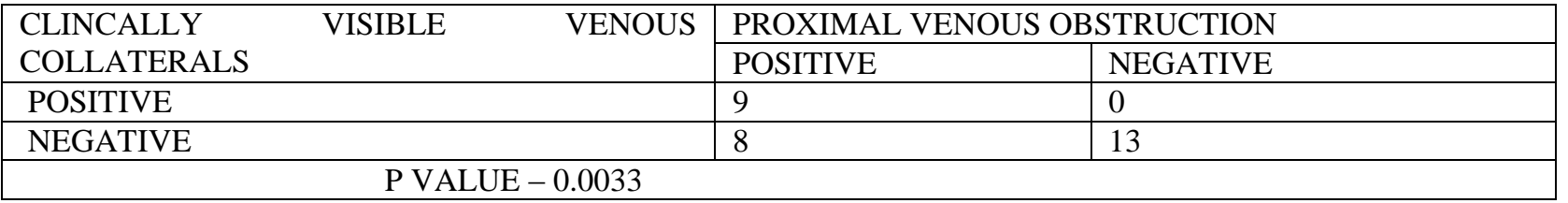


Clearly showing the very high diagnostic role of this simple clinical examination. P value was found to be 0.0033 showing this statistically very significant.

Thus by this results of very high specificity and positive predictive value show the importance of clinical examination even in this modern day practice. But it should be understood from lower sensitivity and negative predictive values, the role of further investigations which should be judiciously used in selective patients for better outcome and cost effectiveness and no conclusions should be drawn in the absence of such a collateral vein during physical examination. ${ }^{6}$

\section{Duplex Evaluation:}

In our study sensitivity and specificity of duplex examination in finding obstruction were $47.06 \%$ and $61.54 \%$ respectively. positive and negative predictive values were $61.54 \%$ and $47.06 \%$ respectively. Although values were lower than usual they are clearly much less than that of clinically visible venous collaterals in specificity and positive predictive values for diagnosing venous obstruction.

Previous history of deep venous thrombosis:-

Eight out of nine patients with venous collaterals had previous history of deep venous thrombosis constituting $88.89 \%$ of cases. Totally 15 patients in our study had previous history of deep venous thrombosis with venous collaterals present in 8 of these patients $53.33 \%$. This shows very good correlation between previous history of deep venous thrombosis and presence of venous collaterals.

\section{Distribution Of Venous Collaterals:-}

\section{Scrotal wall venous collaterals:-}

Two out of nine patients had scrotal wall venous collaterals. Scrotal skin being devoid of subcutaneous fat makes it easy to identify collaterals even in very obese patients but its presence was seen in only $22.22 \%$ of patients.

\section{Groin and pubic collaterals:-}

Groin and pubic collaterals were the more prevalent in our study group constituting $77.78 \%$ and $66.67 \%$ overall.

\section{Abdominal wall collaterals:-}

Abdominal wall collaterals are well seen in patients with Inferior vena cava (IVC) obstruction. 3 out of 17 patients with proximal venous obstruction had IVC obstruction with $66.67 \%$ ( 2 out of 3 ) having venous collaterals. One had bilateral abdominal wall collaterals and other patient to right side. Both these two patients had collaterals going towards upper thoracic wall .Thus prominent abdominal wall collaterals especially on both sides should prompt possibility of IVC obstruction with further thorough evaluation.

Table 3:- Distribution Of Venous Collaterals

\begin{tabular}{|c|c|c|c|}
\hline S.NO & OVERALL & Number & percentage \\
\hline 1 & 1. Groin & $7 / 9$ & $77.78 \%$ \\
\hline 2 & 2. Pubic & $6 / 9$ & $66.67 \%$ \\
\hline 3 & 3. Scrotal & $2 / 9$ & $22.23 \%$ \\
\hline 4 & Abdominal & $2 / 9$ & $22.23 \%$ \\
\hline & \multicolumn{3}{|c|}{ Detailed distribution of individual collaterals } \\
\hline 1 & GROIN & 1 & $11.11 \%$ \\
\hline 2 & PUBIC REGION & 1 & $11.11 \%$ \\
\hline 3 & ABDOMINAL & 1 & $11.11 \%$ \\
\hline 4 & SCROTAL & 0 & $0 \%$ \\
\hline \multirow[t]{2}{*}{5} & COMBINED & 6 & $66.67 \%$ \\
\hline & \multicolumn{3}{|c|}{$\begin{array}{ll}\text { a) Groin + Pubic }-1 & \text { B) Groin +Scrotal }-1 \\
\text { C) Groin + Pubic + Abdominal }-3 & \text { D) Groin + Pubic + Scrotal - } 1\end{array}$} \\
\hline
\end{tabular}

Thus the distribution of these collaterals in pubic, groin, scrotal regions emphasize the thorough clinical evaluation with proper exposure. Unfortunately, most physicians are not inclined to expose groin and lower abdominal wall to look for this signs. 
As presence of collaterals is described as an indication of obstruction ${ }^{5}$ all these patients must be evaluated for proximal venous obstruction, to enable them for effective treatment options like iliac venous stenting, as it relieves symptoms of extremity swelling and pain in the majority of treated patients. ${ }^{3}$

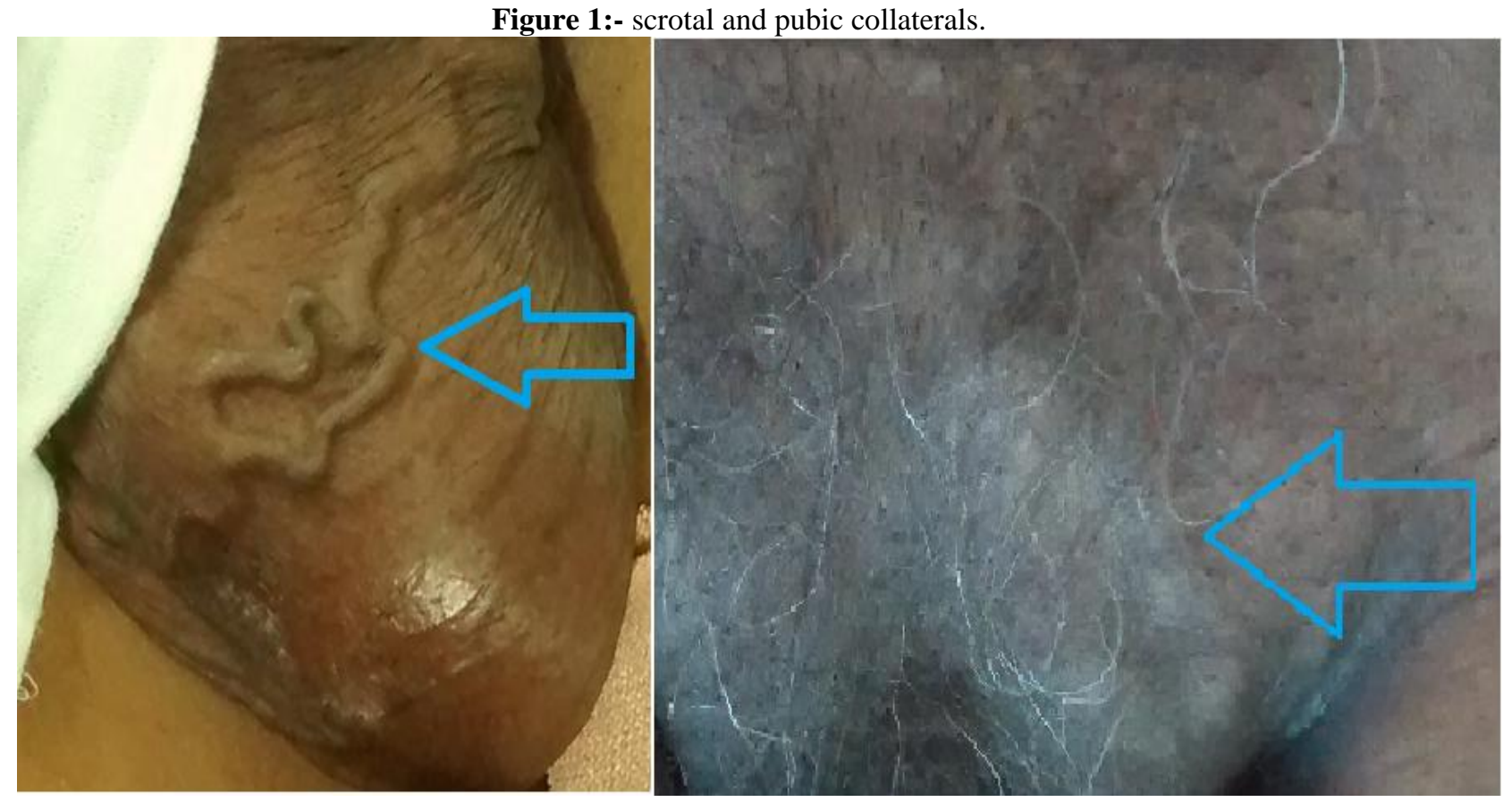

Figure 2:- lateral abdominal wall and groin venous collaterals.

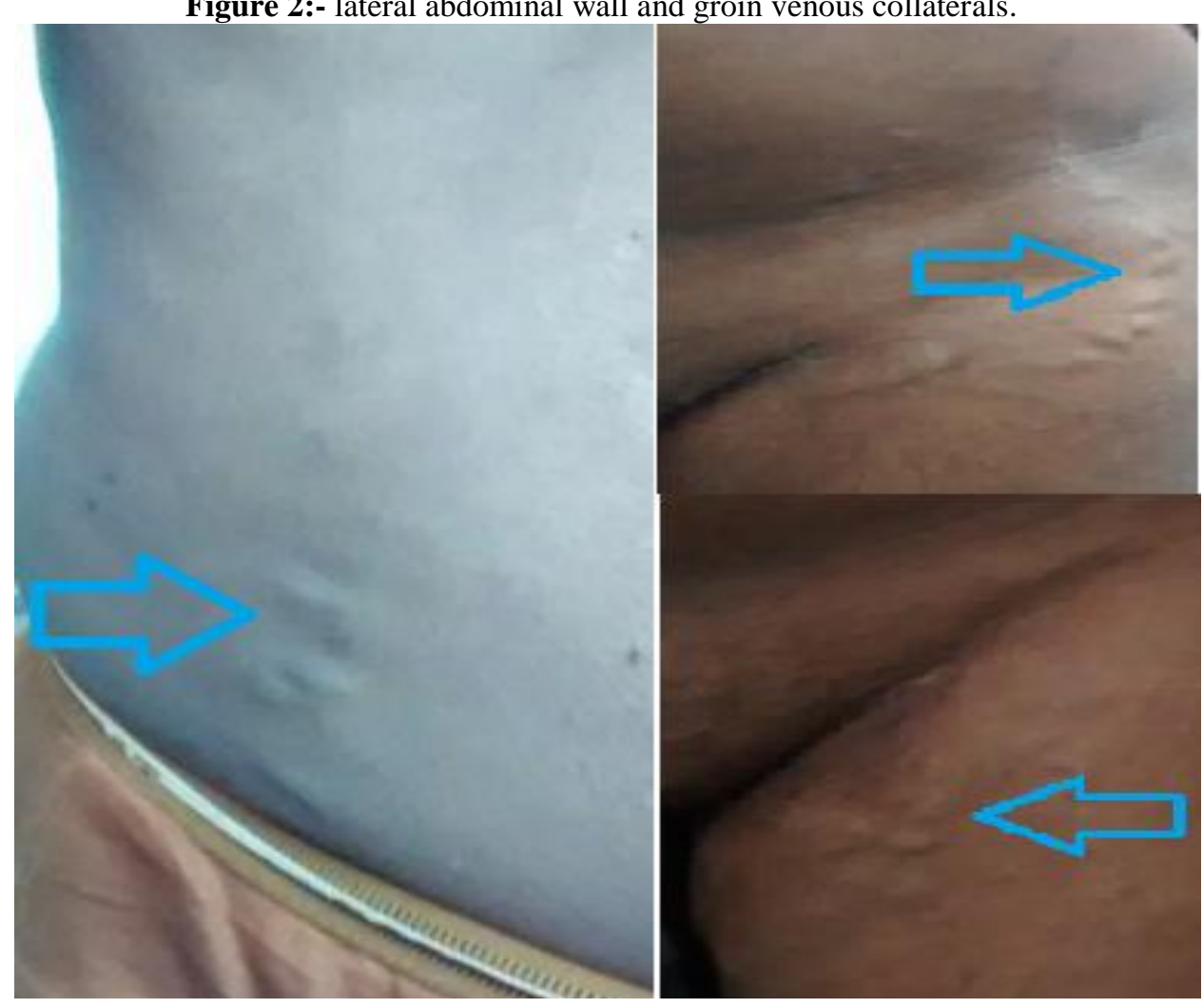


Figure 3:- extensive venous collateralsin inferior vena cava obstruction.

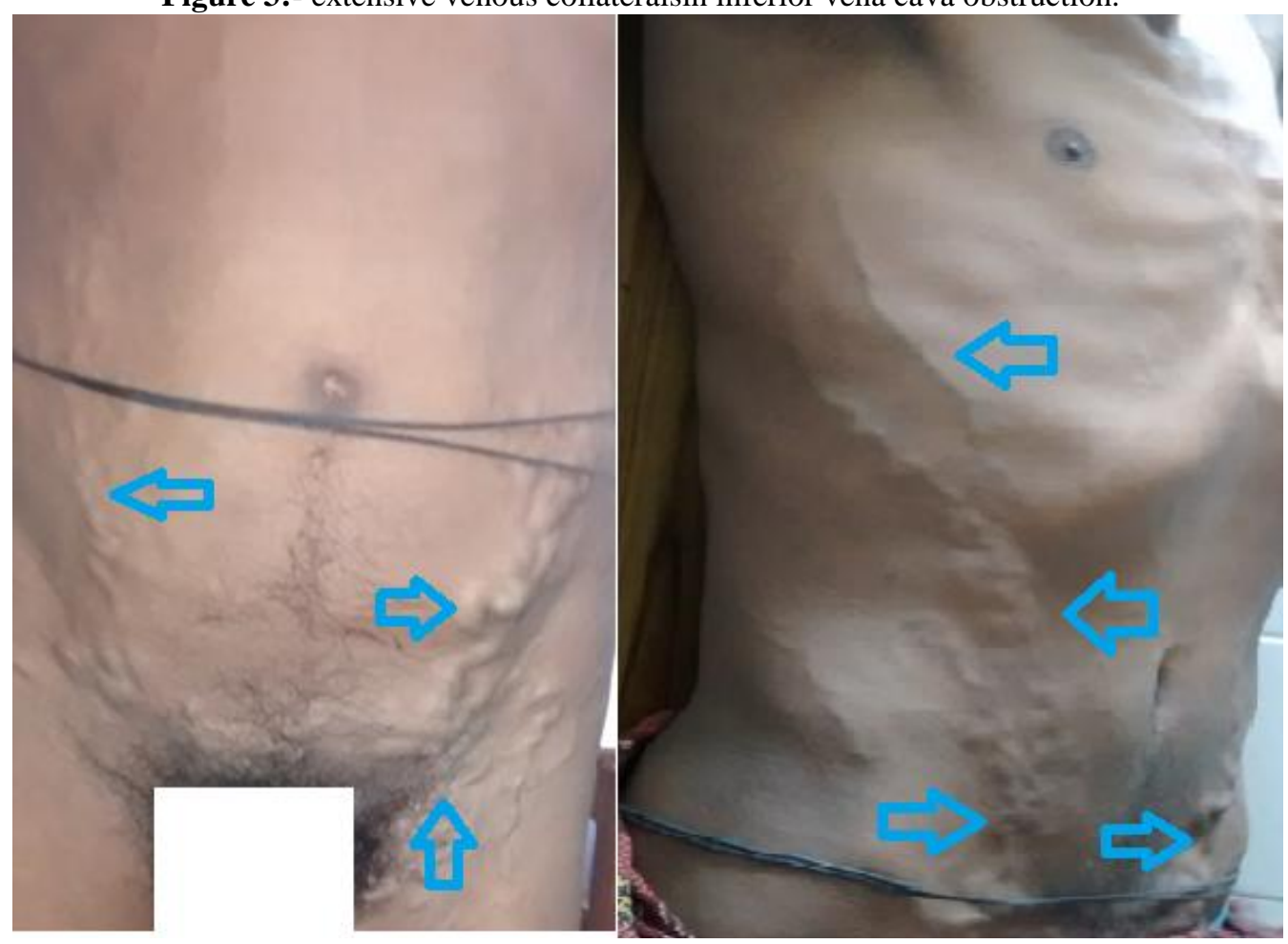

Figure 4:- venous collaterals in venography

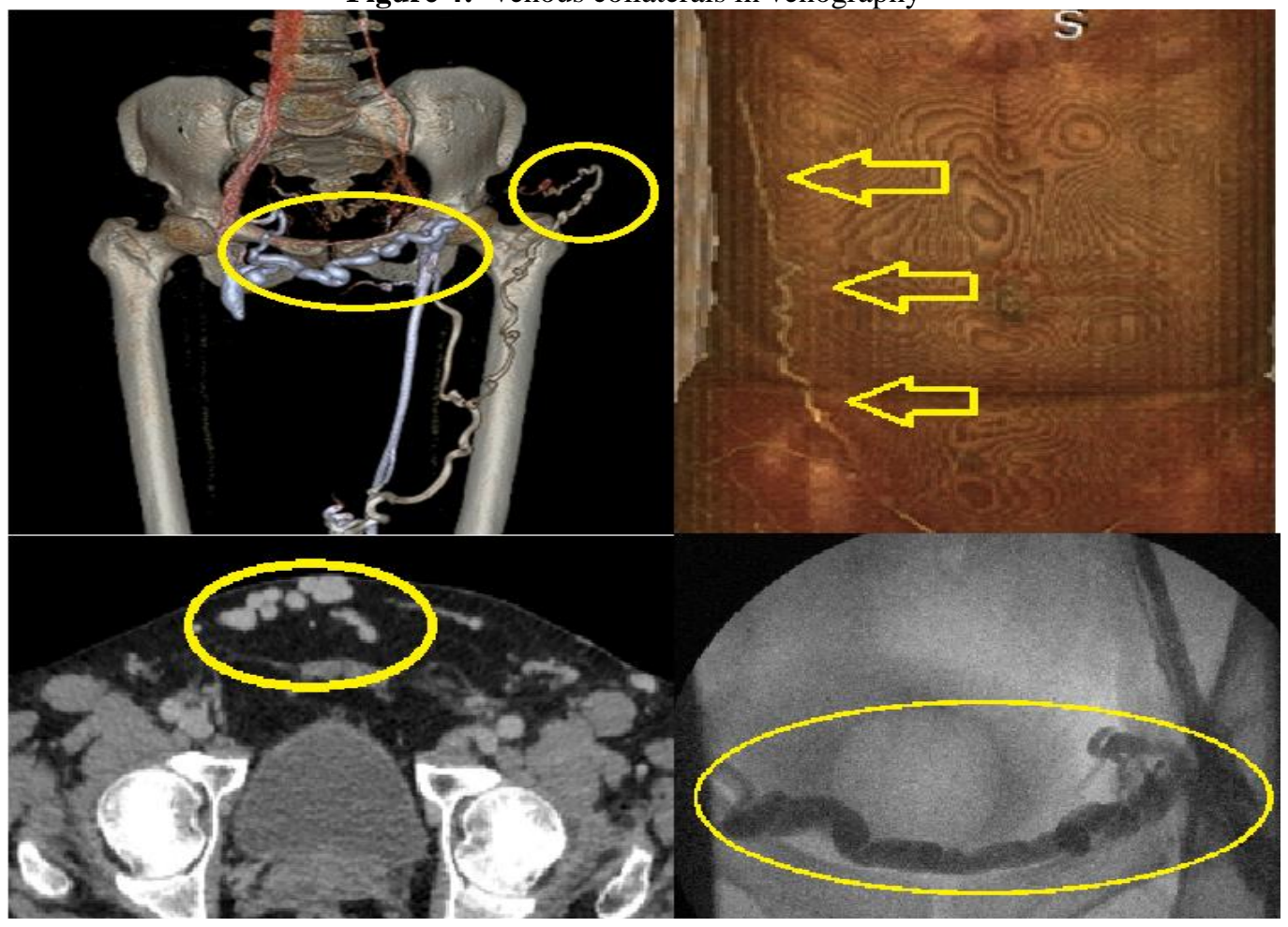




\section{Conclusion:-}

This very high diagnostic value of visible venous collaterals by clinical examination emphasize the fact that even in this era of highly sophisticated diagnostic modalities, basic clinical examination still has significant role, even in today's modern clinical practice.

\section{References:-}

1. Haimovici's Vascular Surgery, 6edition

2. Hallet's Comprehensive.Vascular.and.Endovascular.Surgery, 2nd edition.

3. Hood DB, Alexander JQ. Endovascular management of iliofemoral venous occlusive disease. Surg Clin North Am 2004;84:1381-96

4. Kurstjens et al, Hemodynamic significance of collateral blood flow in chronic venous obstruction, Phlebology 2015;30:27-34

5. M.Lea Thomas et al, Venous collaterals in external and common iliac vein obstruction, clin.radiol.(1967) 18, 403-411.

6. Pagani et al, Computer Tomographic manifestations of abdominal and pelvic venous collaterals. Radiology 142:415-419, Feb 1982

7. Ralph L. M. Kurstjens et al, Abdominal and pubic collateral veins as indicators of deep venous obstruction, $\mathbf{J}$ Vasc Surg: Venous and Lym Dis 2016;4:426-33.

8. Rutherford's vascular surgery, volume- $1,8^{\text {th }}$ edition.

9. Wesley S.Moore's Vascular and Endovascular surgery, $8^{\text {th }}$ edition

10. Wittens et al, Abdominal wall venous collaterals : the latent clinical sign for central venous obstruction,Circulation.2010;122:2089-2090. 